\title{
ACTH-independent macronodular adrenocortical hyperplasia reveals prevalent aberrant in vivo and in vitro responses to hormonal stimuli and coupling of arginine-vasopressin type 1a receptor to $11 \beta$-hydroxylase
}

\author{
Johannes Hofland ${ }^{1 *}$, Leo J Hofland ${ }^{1}$, Peter M van Koetsveld ${ }^{1}$, Jacobie Steenbergen ${ }^{1}$, Wouter W de Herder ${ }^{1}$, \\ Casper $\mathrm{H}$ van Eijck ${ }^{2}$, Ronald $\mathrm{R}$ de Krijger ${ }^{3}$, Francien $\mathrm{H}$ van Nederveen ${ }^{4}$, Maarten $\mathrm{O}$ van Aken ${ }^{5}$, \\ Johannes $\mathrm{W}$ de Groot ${ }^{6}$, Thera $\mathrm{P}$ Links $^{7}$, Frank $\mathrm{H}$ de Jong ${ }^{1}$ and Richard A Feelders ${ }^{1}$
}

\begin{abstract}
Background: Adrenal Cushing's syndrome caused by ACTH-independent macronodular adrenocortical hyperplasia (AIMAH) can be accompanied by aberrant responses to hormonal stimuli. We investigated the prevalence of adrenocortical reactions to these stimuli in a large cohort of AIMAH patients, both in vivo and in vitro.

Methods: In vivo cortisol responses to hormonal stimuli were studied in 35 patients with ACTH-independent bilateral adrenal enlargement and (sub-)clinical hypercortisolism. In vitro, the effects of these stimuli on cortisol secretion and steroidogenic enzyme mRNA expression were evaluated in cultured AIMAH and other adrenocortical cells. Arginine-vasopressin (AVP) receptor mRNA levels were determined in the adrenal tissues.

Results: Positive serum cortisol responses to stimuli were detected in 27/35 AIMAH patients tested, with multiple responses within individual patients occurring for up to four stimuli. AVP and metoclopramide were the most prevalent hormonal stimuli triggering positive responses in vivo. Catecholamines induced short-term cortisol production more often in AIMAH cultures compared to other adrenal cells. Short- and long-term incubation with AVP increased cortisol secretion in cultures of AIMAH cells. AVP also increased steroidogenic enzyme mRNA expression, among which an aberrant induction of CYP11B1. AVP type 1a receptor was the only AVPR expressed and levels were high in the AIMAH tissues. AVPR1A expression was related to the AVP-induced stimulation of CYP11B1.

Conclusions: Multiple hormonal signals can simultaneously induce hypercortisolism in AIMAH. AVP is the most prevalent eutopic signal and expression of its type 1a receptor was aberrantly linked to CYP11B1 expression.
\end{abstract}

Keywords: AIMAH, Cushing's syndrome, Arginine-vasopressin

\section{Background}

Cushing's syndrome (CS) can be divided into adrenocorticotropin (ACTH)-dependent and $\mathrm{ACTH}$-independent disease [1]. The latter can in rare cases result from ACTHindependent macronodular adrenocortical hyperplasia (AIMAH). AIMAH is characterized by multiple bilateral

\footnotetext{
* Correspondence: j.hofland@erasmusmc.nl

${ }^{1}$ Department of Internal Medicine, Section of Endocrinology, P.O. Box 2040,

3000, CA Rotterdam, The Netherlands

Full list of author information is available at the end of the article
}

nodules consisting of hyperplastic adrenal cells that lead to non-ACTH-dependent (over)production of cortisol.

The hypercortisolism in AIMAH patients is caused by an exaggerated or ectopic response to stimulation by hormonal signals. Receptors for these hormones, eutopically or ectopically expressed on adrenocortical cells and activated by endogenous hormones, stimulate intracellular pathways leading to (sub-)clinical CS [2]. Aberrant hormonal responses and the presence of hormone receptors in AIMAH have been well documented for

\section{() Biomed Central}


glucose-dependent insulinotropic polypeptide (GIP) receptor [3-5], $\alpha 4-, \beta 1$ - and $\beta 2$-adrenergic receptor (AR) $[6,7]$, arginine-vasopressin (AVP) type $1 \mathrm{a}$ and 2 receptors $(A V P R 1 A / 2)[8,9]$, luteinizing hormone receptor (LHR) $[10,11]$ and serotonin (5-HT) type 4 receptor (5HT4R) [12,13]. Other possible aberrantly expressed receptors include the AngII type I receptor (AT1R) [14] and glucagon receptor $[15,16]$.

Diagnostic protocols for AIMAH include administration of the various hormones or stimuli to patients [2]. The relevance of these effects has been shown by the results of administration of antagonists to the expressed receptors $[6,10,17]$, confirmation of stimulatory effects of hormones on primary AIMAH cells in vitro and/or the detection of the hormone receptors on AIMAH cells. Furthermore, these effects have been described in adrenocortical adenomas and carcinomas, which can also overexpress receptors responsive to endocrine and/ or paracrine signals [17].

Whereas the presence of aberrant receptors has been firmly established, little is known on the cause of such altered receptor expression and on downstream signals coupling receptor activation to stimulation of cell growth and steroidogenesis [18,19]. Although most patients present sporadically, some AIMAH cases occur in families [20], suggesting a possible genetic background. Investigations in murine models have shown that adrenal overexpression of GIP [21] and LH receptors [22] can lead to AIMAH and adrenal CS. This implies that the aberrant expression of these GPCRs may play a role in adrenal cell hyperplasia apart from modulating cortisol production. Most evidence on AIMAH pathophysiology in humans has been collected from case reports, small case series and reviews; only three centers have reported on larger groups of 16, 18 and 32 AIMAH patients, respectively $[7,16,19]$. Furthermore, no large series have systematically related clinical data to corresponding in vitro findings.

The current study evaluated the presence of aberrant hormonal responses in patients with AIMAH in order to discover novel pathways involved in the pathophysiology of this rare disease. We performed in vivo and in vitro stimulation tests with ACTH and multiple ligands for hormone receptors in the largest group of AIMAH patients described so far.

\section{Subjects and methods Patients}

We included patients that presented with ACTHindependent bilateral adrenal enlargement with (sub-)clinical CS between 1994 and 2011. Clinical CS was defined by the presence of clinical symptoms and positive tests for hypercortisolism: the absence of a cortisol diurnal rhythm, increased $24 \mathrm{~h}$ urinary free cortisol excretion, suppressed
ACTH levels and/or failure to suppress cortisol levels below $50 \mathrm{nmol} / \mathrm{l}$ after $1 \mathrm{mg}$ dexamethasone overnight. Subclinical CS was defined by one or more positive tests for hypercortisolism in the absence of overt signs and symptoms of CS according to [23]. The study was approved by the medical ethical committee of the Erasmus $\mathrm{MC}$ and is in accordance with the use of residual tissues according to the Medical Research Involving Human Subjects Act.

All patients were admitted for measurement of baseline hormonal levels and subsequent administration of hormonal stimuli: $250 \mu \mathrm{g}$ synacthen (Novartis, Basel, Switzerland) iv, $100 \mu \mathrm{g}$ LH releasing hormone (LHRH, Ferring, Hoofddorp, The Netherlands) iv, $200 \mu \mathrm{g}$ thyrotropin releasing hormone (TRH, Ferring) iv, a $2 \mathrm{~h}$ upright posture test, $10 \mathrm{mg}$ metoclopramide (Pharmachemie, Haarlem, The Netherlands) orally, $1 \mathrm{mg}$ glucagon (Novo Nordisk, Alphen aan den Rijn, The Netherlands) iv, intravenous salt loading $(\mathrm{NaCl} 3 \%$ at $0.1 \mathrm{cc} / \mathrm{kg} / \mathrm{min})$ and a standard mixed meal (116 g carbohydrates, $27 \mathrm{~g}$ proteins, $14 \mathrm{~g}$ fat). From 2002 on, the intravenous salt loading test was replaced by intramuscular injection of 10 IU AVP (Ferring) [2]. ACTH levels were measured during the upright posture, intravenous salt loading and vasopressin tests to exclude effects of AVP on pituitary ACTH secretion. In case of clinical CS patients underwent bilateral laparoscopic adrenalectomy and were put on lifelong glucocorticoid and mineralocorticoid replacement.

\section{Tissue processing}

Adrenal tissue was collected following adrenalectomy due to renal cell carcinoma (normal, $n=3$ ), AIMAH $(\mathrm{n}=22)$, ACTH-dependent hyperplasia $(\mathrm{n}=11)$, adrenocortical adenoma $(n=11)$ or carcinoma $(n=4)$. Parts of the tissue were stored at $-80^{\circ} \mathrm{C}$ until RNA isolation. Other tissue parts were minced and transferred to a tube containing DMEM/F12 containing 5\% fetal calf serum (FCS), penicillin and streptomycin (Invitrogen, Carlsbad, USA). Subsequently, tissues were dispersed into single primary adrenal cell suspensions using collagenase type I (Sigma-Aldrich, St. Louis, USA) as previously described [24]. Adrenal cell viability was checked with trypan blue and always exceeded 90\%. 1,000,000 cells were put into $5 \mathrm{ml}$ tubes for short-term incubations and, in case of sufficient cell yield, plated in 24 well plates at 100,000 cells per well for long-term culture.

\section{Short-term incubation}

The cells were incubated in quadruplicate in a $2 \mathrm{ml}$ volume containing 5\% FCS with the following secretagogues: vehicle, ACTH, GIP (Sigma), metoclopramide, hCG (Organon, Oss, The Netherlands), epinephrine, norepinephrine (Centrafarm, Etten-Leur, The Netherlands), glucagon, AVP (Monarch Pharmaceuticals, Bristol, USA), desmopressin (Ferring), AngII (Sigma) or TSH (Genzyme, 
Naarden, The Netherlands). The PKA stimulator forskolin (FSK, Sigma) was added as a positive control. Secretagogues were selected on the basis of positive in vivo responses obtained in individual AIMAH patients. After the addition of hormones, tubes were incubated in a rocking water bath at $37^{\circ} \mathrm{C}$ for $2 \mathrm{~h}$. Supernatants were removed and stored at $-20^{\circ} \mathrm{C}$ until the measurement of cortisol.

\section{Long-term cell culture}

Cells were allowed to attach overnight and the medium was changed to serum free DMEM/F12 the next day. After $24 \mathrm{~h}$ the hormonal stimuli also used for short-term incubation were added in quadruplicate and cells were cultured at $37^{\circ} \mathrm{C}$ for $48 \mathrm{~h}$. Subsequently, supernatants were removed and stored at $-20^{\circ} \mathrm{C}$, whereas the attached cells were stored at $-80^{\circ} \mathrm{C}$ until the isolation of RNA.

\section{Cortisol measurement and quantitative mRNA analysis}

Cortisol levels were measured using a chemiluminescencebased method (Immulite, Siemens Diagnostics, Deerfield, USA; reference values for serum 200-800 nmol/l; for urine $<850 \mathrm{nmol} / 24 \mathrm{~h}$ ). RNA was isolated from plated cells and frozen adrenal tissue samples and reverse-transcribed as previously described [25]. The assays for the measurement of mRNA expression of the housekeeping gene HPRT1, the cholesterol transporter steroid acute regulatory protein $(S T A R)$ and steroidogenic enzymes (cytochrome P450 side chain cleavage [CYP11A1], 3 $\beta$-hydroxysteroid dehydrogenase type 2 [HSD3B2], 17-hydroxylase/17,20lyase [CYP17A1], 21-hydroxylase [CYP21A2] and 11 $\beta$ hydroxylase [CYP11B1]) were as reported [26]. We used SYBR green-based assays for measurements of $A V P R 1 A$ (F:TTTGTGATCGTGACGGCTTACA, R:GGTGATGGT AGGGTTTTCCGA) and AVPR1B (F:CAGCAGCATCA ACACCATCT, R:CCATGTAGATCCAGGGGTTG) and purchased the AVPR2 assay from Applied Biosystems (Hs00181055_m1). Positive controls for the assays for the vasopressin receptors consisted of human adrenal gland, kidney and pituitary gland, all obtained as residual tissues during surgical procedures within the Erasmus MC. Quantitative PCR was performed in a $12.5 \mu \mathrm{l}$ mixture containing 20 ng cDNA [26]. PCR efficiency exceeded $90 \%$ for all assays used. mRNA levels were calculated relative to that of HPRT1, expression of which was shown to be stable under the conditions used, on the basis of the $\delta$ Ct-method.

\section{Data analysis and statistics}

A full response was defined as a more than 50\% increase of cortisol following the administration of the stimulus. Responses between 25-50\% were considered as partial [2]. Group comparisons were made with Kruskal-Wallis followed by Dunn's multiple comparison tests. Differences between 2 groups were analyzed by Mann-
Whitney $\mathrm{U}$ or Wilcoxon signed rank tests for unpaired and paired observations, respectively. Spearman's correlation coefficient was used for analysis of association between variables. Multiple testing was adjusted for by Bonferroni correction. All tests were calculated as twotailed and a P-value below 0.05 was considered to be statistically significant.

\section{Results}

\section{In vivo studies}

Thirty-five AIMAH patients underwent in vivo evaluation of cortisol responses to eutopic and ectopic hormonal stimuli. Patient characteristics and basal hormone levels are summarized in Table 1 and Additional file 1: Table S1. All cases appeared to be sporadic; however familial screening was not performed. As expected, midnight serum cortisol levels, cortisol following dexamethasone overnight and 24 hour urinary free cortisol were all higher in patients with clinical compared to subclinical CS (all $\mathrm{p}<0.01$, Table 1). Of note, in patients with subclinical CS urinary free cortisol levels were within the normal range whereas the dexamethasone suppression test was disturbed in the majority of patients. ACTH levels were suppressed in 39\% of patients with subclinical CS. Adrenal diameters were larger in clinical CS patients than in subclinical CS $(\mathrm{P}<0.05$, Table 1$)$.

ACTH administration increased serum cortisol 5.2 \pm 0.9 fold compared to baseline (mean \pm SEM, $\mathrm{p}<0.0001$ ); positive responses were demonstrated in all but one patient. A single ACTH stimulation test in this patient with subclinical CS increased cortisol levels from $191 \mathrm{nM}$ to only 211 nM. Of the additional hormonal stimuli tested, AVP gave the highest percentage of responses: $52 \%$ of patients displayed a $>50 \%$ increase in cortisol levels. The other prevalent responses are also shown in Table 2 and the cortisol induction by these stimuli is indicated in Figure 1A. Overall, significant induction of cortisol was found for AVP, upright posture, metoclopramide, LHRH, glucagon and salt loading.

Twenty-seven (77\%) patients showed a minimum of one full response to any administrated stimulus, apart from ACTH. One, 2, or 3 positive responses were demonstrated in 10, 11 and 5 patients, respectively. One patient had a positive response to 4 aberrant stimuli at in vivo testing (Table 2). Of the 26 patients that underwent an upright posture test and either salt loading or stimulation with AVP, 9 patients had discordant results, 5 (19\%) of whom had only a complete response of serum cortisol to the upright posture test. Manipulation of angiotensin II or $\beta$-adrenergic receptors was not carried out in patients.

The cortisol responses to a standard mixed meal were inversely associated with the morning cortisol levels $(\mathrm{r}=-0.473, \mathrm{p}=0.007)$ and correlated positively 


\begin{tabular}{ll} 
Table $\mathbf{1}$ Characteristics of AIMAH patients evaluated \\
in vivo & \\
\hline Total & $\mathbf{3 5}$ \\
\hline Male/female & $9 / 26$ \\
Age (years) & $56.1 \pm 9.8$ \\
Adrenalectomy & $22(63 \%)$ \\
Hypercortisolism & \\
- SCS & $13(37 \%)$ \\
- CCS & $22(63 \%)$ \\
Diameter adrenal (mm) & \\
- left SCS & $31.7 \pm 10.1$ \\
- left CCS & $46.1 \pm 16.9^{*}$ \\
- right SCS & $27.2 \pm 8.8$ \\
- right CCS & $43.6 \pm 17.0^{*}$ \\
Hypertension & \\
- SCS & \\
- CCS & $7.47 \pm 0.92(39 \% \mathrm{nd})$ \\
Diabetes mellitus & $145 \pm 0.89(85 \% \mathrm{nd})$ \\
- SCS & \\
- SCS & $17(77 \%)$ \\
- CCS &
\end{tabular}

SCS: subclinical Cushing's syndrome, CCS: clinical Cushing's syndrome, URL: upper reference limit, nd: non-detectable, data presented as mean $\pm S D$, ${ }^{*} \mathrm{P}<0.05$, compared to SCS. " ACTH levels below the lower detection limit of $1.10 \mathrm{pmol} / \mathrm{l}$ were set at $0.55 \mathrm{pmol} / \mathrm{l}$.

with the responses to ACTH $(r=0.435, p=0.018)$. There were no significant differences in cortisol induction following the hormonal stimuli between patients with subclinical and clinical CS.

\section{Short-term in vitro studies}

Cells for short-term $(2 \mathrm{~h})$ primary incubations were successfully obtained from the resected adrenal tissues in 14 out of 22 (64\%) operated AIMAH patients (Table 3). Due to limited availability of cells, cultures could not be incubated with the complete panel of secretagogues (Additional file 1: Table S1). Incubation with ACTH $(500 \mathrm{pg} / \mathrm{ml})$ induced a full response in $60 \%$ of cultures. Augmented supernatant cortisol levels were found in 1 out of 4 cultures (25\%) incubated with $100 \mathrm{nM}$ AVP. In comparison, short-term metoclopramide incubation gave a full response in 2 out of 7 (29\%) primary cultures. Norepinephrine, glucagon, desmopressin, hCG, angiotensin II and TSH did not augment cortisol secretion above $50 \%$ in any of the cultures investigated.

The mean cortisol induction was significant after 50 and $500 \mathrm{pg} / \mathrm{ml}$ ACTH $(2.82 \pm 0.98$-fold, $\mathrm{p}=0.018$ and $2.06 \pm 0.27$ fold, $\mathrm{p}=0.005)$, FSK $(2.31 \pm 0.41$-fold, $\mathrm{p}=0.005)$ and norepinephrine (1.16 \pm 0.04 -fold, $\mathrm{p}=0.016)$, but not for the other stimuli (Figure 1B). Overall associations between hormonal effects obtained in vivo and in vitro were not significant for any of the stimuli investigated (Table 3). Similarly, tissues of patients who showed a complete response for a particular stimulus in vivo did not show higher cortisol levels after incubation with the hormonal equivalent compared to non-responders.

Short-term incubations were also performed with cells from 19 other adrenal tissues, consisting of 1 normal adrenal gland, $10 \mathrm{ACTH}$-dependent hyperplasias and 8 adrenocortical adenomas (Table 3 and Figure 1B). In vivo investigations were not available for these patients. In vitro responses to all individual stimuli were not significantly different between adrenal hyperplasia and adenoma samples. Full or partial cortisol responses were only observed after incubation with ACTH, FSK, AngII, AVP, metoclopramide and GIP. Only the mean cortisol responses to epinephrine and norepinephrine were significantly higher in AIMAH cultures than in the nonAIMAH cultures $(\mathrm{P}<0.05$, Figure $1 \mathrm{~B})$.

\section{Long-term in vitro studies}

Seven AIMAH tissues yielded sufficient cells to perform concurrent $48 \mathrm{~h}$ incubations with hormonal stimuli. The cortisol responses are shown in Table 4 and Additional file 1: Table S1. Again AVP (86\%) and metoclopramide (50\%) were the non-ACTH stimuli that most often led to $>50 \%$ increases in cortisol levels. The mean induction of cortisol was only significant following the addition of ACTH (4.55 \pm 1.51 -fold, $\mathrm{p}=0.016)$ and $100 \mathrm{nM}$ AVP $(2.21 \pm 0.32$-fold, $\mathrm{p}=0.016$ ), see Figure 1C; the sample sizes for the other groups were small. Again, there was a poor overall correlation between effects obtained in vivo and in vitro (Table 4). Cortisol levels did not increase after incubation of cells from the in vivo responders with the corresponding stimuli. 
Table 2 In vivo response to hormonal stimuli in patients with AIMAH

\begin{tabular}{|c|c|c|c|}
\hline Stimulus & $\mathrm{n}$ tested & Partial response $(25-50 \%)$ n (\%) & Full response $\geq 50 \%$ ) $n(\%)$ \\
\hline $\mathrm{ACTH}_{1-24}$ & 29 & - & $28(97 \%)$ \\
\hline Posture & 26 & $4(15 \%)$ & $13(50 \%)$ \\
\hline Salt loading & 6 & $1(17 \%)$ & $1(17 \%)$ \\
\hline AVP & 21 & $6(29 \%)$ & $12(52 \%)$ \\
\hline Metoclopramide & 29 & $3(10 \%)$ & $7(24 \%)$ \\
\hline $\mathrm{LHRH}$ & 30 & $5(17 \%)$ & $5(17 \%)$ \\
\hline TRH & 29 & $2(7 \%)$ & $3(10 \%)$ \\
\hline Glucagon & 26 & $4(15 \%)$ & $4(15 \%)$ \\
\hline Mixed meal & 32 & $2(6 \%)$ & $6(18 \%)$ \\
\hline \multicolumn{2}{|c|}{ Number of aberrant responses } & $\mathrm{n}$ & $\mathrm{n}$ \\
\hline \multicolumn{2}{|l|}{0} & 20 & 8 \\
\hline \multicolumn{2}{|l|}{1} & 8 & 10 \\
\hline \multicolumn{2}{|l|}{2} & 4 & 11 \\
\hline \multicolumn{2}{|l|}{3} & 3 & 5 \\
\hline \multicolumn{2}{|l|}{4} & 0 & 1 \\
\hline
\end{tabular}

We evaluated the effects of the hormonal stimuli on mRNA levels of STAR and the steroidogenic enzymes involved in cortisol synthesis (Figure 2). ACTH and AVP at $100 \mathrm{nM}$ stimulated the expression of the cholesterol transporter and all steroidogenic enzymes studied in the AIMAH cultures. Although stimulatory effects were also found for the other secretagogues, these effects did not reach statistical significance, likely due to the small sample size $(n \leq 4)$.

For this reason, we focused further on AVP and concurrently measured AVP effects in long-term adrenal cell cultures of non-AIMAH origin (i.e. 3 normal adrenals, 1 ACTH-dependent hyperplasia, 3 adenomas and 4 carcinomas). AVP at $100 \mathrm{nM}$ significantly increased cortisol secretion in the 7 primary adrenal cell cultures with detectable supernatant cortisol levels $(2.54 \pm 0.69$-fold, $\mathrm{p}=0.016)$. AVP induced a $>50 \%$ increase in cortisol levels in $71 \%$ of non-AIMAH adrenal cultures. The effects on steroidogenic enzyme mRNA expression after the addition of AVP were comparable between cultures from AIMAH cells and other adrenocortical tissues, with the exception of CYP11B1 (Figure 2). $48 \mathrm{~h}$ culture in the presence of AVP stimulated CYP11B1 expression 6.34 \pm 1.57 -fold in AIMAH cells, compared to a $2.66 \pm 0.97$-fold induction in cells of non-AIMAH adrenal origin $(\mathrm{p}=0.033)$. AVP-stimulated cortisol and $C Y P 11 B 1$ levels were equal among the different groups of non-AIMAH tissues.

\section{AVP receptor expression}

Expression of mRNA of vasopressin receptors (AVPR1A, $A V P R 2, A V P R 1 B)$ was studied in a panel of adrenocortical tissues, consisting of AIMAH, normal adrenals, ACTH- dependent hyperplasias, adenomas and carcinomas. The $\mathrm{V}_{3}$ $(A V P R 1 B)$ was not detectable in any of the adrenocortical tissues studied, whereas $\mathrm{V}_{2}$ (AVPR2) mRNA was detectable in 10 out of the 29 samples, distributed among all groups, but at very low levels (Ct values $>38$ ). The ubiquitously expressed AVPR1A mRNA was found to be highest in the AIMAH samples. The expression levels in AIMAH were significantly increased compared to those in adrenocortical carcinomas ( $\mathrm{p}=0.037$, Figure 3A). AIMAH AVPR1A levels were not associated with clinical characteristics or the in vivo or in vitro cortisol induction following upright posture or AVP administration ( $\mathrm{p}>0.05)$. On the other hand, $A V P R 1 A$ levels in all tissues were significantly associated with the in vitro induction of CYP11B1 by $100 \mathrm{nM}$ AVP $(\mathrm{r}=0.76, \mathrm{p}=0.006$, Figure 3B).

\section{Discussion}

AIMAH is a rare disease associated with the presence of aberrantly expressed eutopic and ectopic receptors on adrenocortical cells [2]. In the current study, ACTH still formed the most potent stimulus for steroidogenesis in AIMAH. ACTH stimulated cortisol production in vivo and in vitro in almost all patients. One patient showed only $10 \%$ increase in cortisol levels following $\mathrm{ACTH}$. Unfortunately, repetitive testing was not available and incorrect administration or sample handling cannot be excluded in this case. The induction of cortisol by ACTH was comparable in primary cultures of AIMAH and nonAIMAH origin. We have previously demonstrated that MC2R levels, which are controlled by ACTH signaling through cAMP $[27,28]$, are equal in AIMAH and other adrenal tissues [29]. Although plasma ACTH levels are low 
Hofland et al. Orphanet Journal of Rare Diseases 2013, 8:142

Page 6 of 12

http://www.ojrd.com/content/8/1/142

A
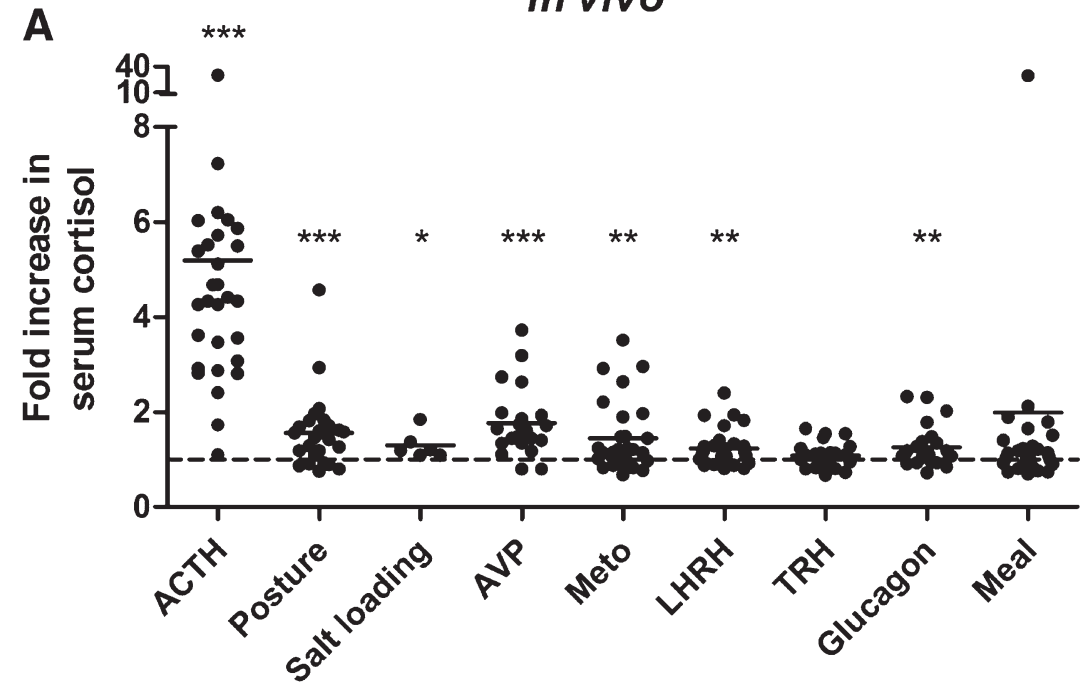

B

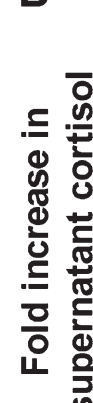

C

들 in vivo

in vitro short-term
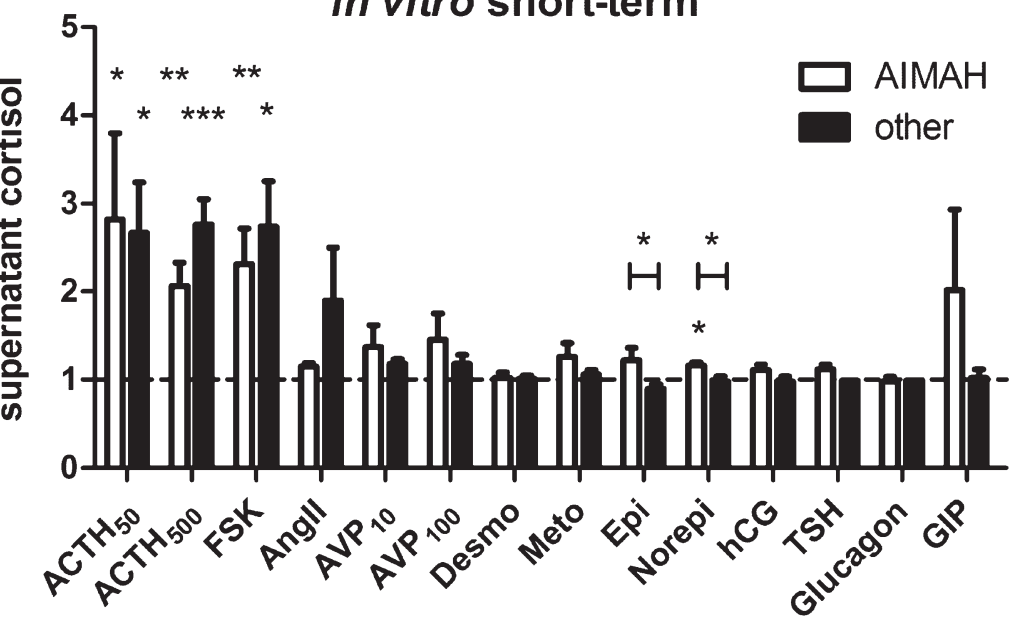

in vitro long-term

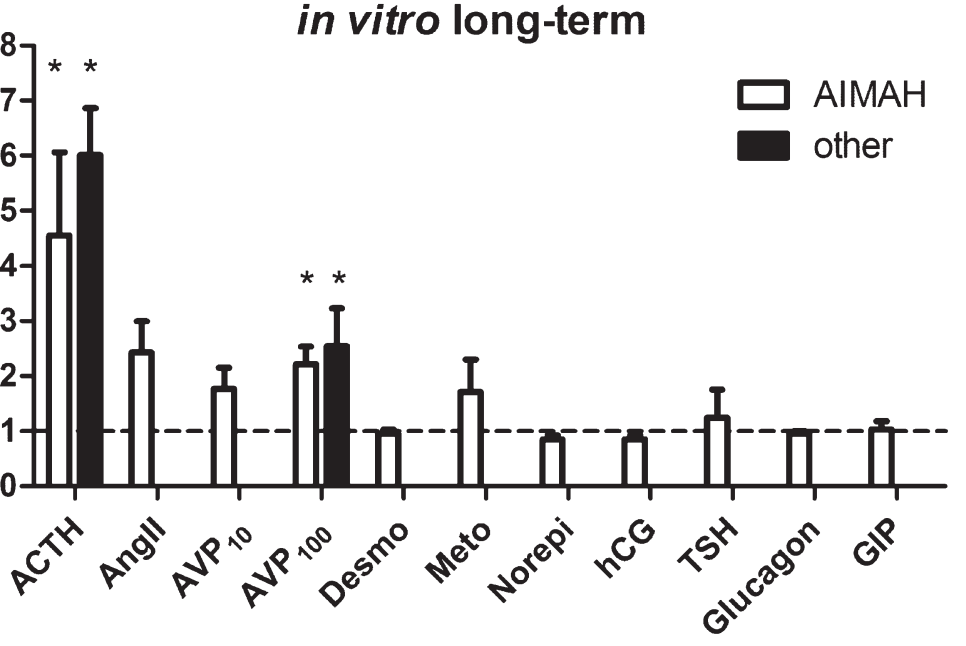

Figure 1 (See legend on next page.) 
(See figure on previous page.)

Figure 1 In vivo and in vitro induction of cortisol production following administration of hormonal stimuli. (A) Patients were tested for the presence of aberrant expression of eutopic or ectopic hormone receptors by the administration of hormonal stimuli in various tests indicated on the X-axis. Line represents mean. ${ }^{*} p<0.05,{ }^{* *} p<0.01,{ }^{* * *} p<0.001$ compared to basal level (Wilcoxon signed rank test). (B) Primary cell cultures from AIMAH tissues (white bars) or from normal adrenals, ACTH-dependent adrenocortical hyperplasia or adenomas (other, black bars) were incubated for $2 \mathrm{~h}$ in the presence of specific hormone receptor agonists indicated on the X-axis. Concentrations used have been summarized in Table 3. Data are represented as mean+SEM. ${ }^{*} p<0.05,{ }^{* *} p<0.01,{ }^{* * *} p<0.001$ compared to vehicle control (Wilcoxon signed rank) or between pathological entities (Mann-Whitney $\mathrm{U}$ test). (C) Cortisol induction in media of AIMAH or other adrenal cells after $48 \mathrm{~h}$ incubation with specific hormone receptor agonists. Concentrations used are summarized in Table 4. Data are represented as mean+SEM. * $\mathrm{p}<0.05$ compared to vehicle control (Wilcoxon signed rank). Numbers of patients are shown in Tables 2, 3 and 4.

or undetectable in AIMAH patients, other GPCR-coupled pathways in AIMAH cells could stimulate cAMP formation and thereby ensure MC2R expression.

The most prevalent exaggerated responses to hormonal stimulation in AIMAH patients were to AVP and upright posture, confirming previous findings [16]. Several studies have now demonstrated the presence of the eutopically expressed $V_{1}$ receptor in AIMAH tissues [9,30]. The (near) undetectable levels of $\mathrm{V}_{2}$ and $\mathrm{V}_{3}$ receptors combined with the absence of effects of desmopressin, a selective $\mathrm{V}_{2}$ agonist, plead against significant roles of these latter receptors in AIMAH. Although no overall significant differences in AVPR1A mRNA levels between AIMAH and other adrenal cells were detected [9,30], individual patients could still overexpress the $\mathrm{V}_{1}$ receptor [31-33]. AVP induced cortisol and mRNA expression of StAR and four steroidogenic enzymes uniformly in AIMAH and nonAIMAH cells, suggesting that AVP has a physiological effect on adrenocortical steroidogenesis. However, the selective stimulation of CYP11B1, a key enzyme in cortisol synthesis, in AIMAH by AVP indicates a novel molecular mechanism underlying the coupling between the $\mathrm{V}_{1}$ receptor and steroidogenesis in AIMAH. This suggestion is supported by the association between $A V P R 1 A$ levels and the AVP-induced mRNA expression of CYP11B1. This correlation between receptor levels and cortisol stimulation is not present for MC2R and ACTH [29]. More efficient coupling of the V1 receptor to $11 \beta$-hydroxylase could form a cause of AIMAH that is characterized by normal GPCR levels. These findings in AIMAH might open up new opportunities for medical treatment with selective $\mathrm{V}_{1}$ receptor antagonists [34]. Adrenocortical carcinomas seem to have an impaired response to AVP, possibly due to decreased expression of the type $V_{1}$ receptor.

The upright posture test was positive in half of the patients studied in vivo. Of the 13 patients with a positive response to upright posture, 8 reacted also positively to AVP administration. The other 5 patients could have

Table 3 Two hour in vitro cortisol responses to hormonal stimuli in primary adrenal cell cultures

\begin{tabular}{|c|c|c|c|c|c|c|c|c|}
\hline & \multirow[b]{2}{*}{ Dose } & \multicolumn{3}{|c|}{ AIMAH } & \multirow[b]{2}{*}{$\begin{array}{c}\text { Correlation with in vivo } \\
\text { test }\end{array}$} & \multicolumn{3}{|c|}{ Non-AIMAH } \\
\hline & & $n$ & $\begin{array}{c}\text { Partial response } \\
(\%)\end{array}$ & $\begin{array}{c}\text { Full response } \\
(\%)\end{array}$ & & $n$ & $\begin{array}{c}\text { Partial response } \\
(\%)\end{array}$ & $\begin{array}{c}\text { Full response } \\
(\%)\end{array}$ \\
\hline $\mathrm{ACTH}_{1-24}$ & $50 \mathrm{pg} / \mathrm{ml}$ & 7 & $2(29 \%)$ & $4(57 \%)$ & 0.30 & 5 & $1(20 \%)$ & $4(80 \%)$ \\
\hline $\mathrm{ACTH}_{1-24}$ & $\begin{array}{l}500 \mathrm{pg} / \\
\mathrm{ml}\end{array}$ & 10 & $3(30 \%)$ & $6(60 \%)$ & 0.07 & 18 & $1(6 \%)$ & $16(89 \%)$ \\
\hline FSK & $1 \mu \mathrm{M}$ & 8 & 0 & $7(88 \%)$ & 0.29 & 9 & 0 & $7(78 \%)$ \\
\hline Angll & $10 \mathrm{nM}$ & 2 & 0 & 0 & n.a. ${ }^{\#}$ & 2 & $1(50 \%)$ & $1(50 \%)$ \\
\hline AVP & $10 \mathrm{nM}$ & 6 & $2(33 \%)$ & $1(17 \%)$ & $-0.72^{\dagger} ;-0.50^{\#}$ & 4 & $1(25 \%)$ & 0 \\
\hline AVP & 100 nM & 4 & $1(25 \%)$ & $1(25 \%)$ & $-1.00^{\dagger} ;-0.80^{\#}$ & 3 & $1(33 \%)$ & 0 \\
\hline Desmopressin & $10 \mathrm{nM}$ & 5 & 0 & 0 & -0.80 & 3 & 0 & 0 \\
\hline Metoclopramide & $1 \mu \mathrm{M}$ & 7 & 0 & $2(29 \%)$ & 0.71 & 14 & $3(21 \%)$ & 0 \\
\hline Epinephrine & $1 \mu \mathrm{M}$ & 7 & $1(14 \%)$ & $1(14 \%)$ & $-0.50^{\#}$ & 5 & 0 & 0 \\
\hline Norepinephrine & $1 \mu \mathrm{M}$ & 7 & $1(14 \%)$ & 0 & $-0.15^{\#}$ & 5 & 0 & 0 \\
\hline hCG & $100 \mathrm{IU} / \mathrm{ml}$ & 10 & $3(30 \%)$ & 0 & 0.60 & 4 & 0 & 0 \\
\hline TSH & $10 \mathrm{nM}$ & 4 & 0 & 0 & -0.32 & 1 & 0 & 0 \\
\hline Glucagon & $1 \mu \mathrm{M}$ & 4 & 0 & 0 & 0.50 & 1 & 0 & 0 \\
\hline GIP & $100 \mathrm{nM}$ & 6 & $1(17 \%)$ & $1(17 \%)$ & $0.49^{\natural}$ & 4 & $1(25 \%)$ & 0 \\
\hline
\end{tabular}

" standard mixed meal, ${ }^{*}$ upright posture test, ${ }^{\dagger}$ AVP im, n.a.: not applicable. 
Table 4 Forty-eight hour in vitro cortisol responses to hormonal stimuli in AIMAH cells

\begin{tabular}{|c|c|c|c|c|c|c|}
\hline & Dose & $\mathrm{n}$ & Partial response $\mathrm{n}(\%)$ & Full response $\mathrm{n}(\%)$ & Correlation with in vivo test & Correlation with $\mathrm{t}=2 \mathrm{~h}$ \\
\hline $\mathrm{ACTH}_{1-24}$ & $10 \mathrm{ng} / \mathrm{ml}$ & 7 & 0 & $6(86 \%)$ & -0.39 & 0.20 \\
\hline Angll & $100 \mathrm{nM}$ & 4 & 0 & $4(100 \%)$ & $1.00^{* * \#}$ & n.a. \\
\hline AVP & $10 \mathrm{nM}$ & 3 & 0 & $2(67 \%)$ & $0.50^{\dagger}$; n.a." & n.a. \\
\hline AVP & $100 \mathrm{nM}$ & 7 & $1(14 \%)$ & $6(86 \%)$ & $-0.18^{\dagger} ;-0.086^{\#}$ & -0.50 \\
\hline Desmopressin & $10 \mathrm{nM}$ & 5 & 0 & 0 & -0.67 & $1.00^{* *}$ \\
\hline Metoclopramide & $1 \mu \mathrm{M}$ & 4 & 0 & $2(50 \%)$ & 0.60 & $1.00^{* *}$ \\
\hline Norepinephrine & $1 \mu \mathrm{M}$ & 4 & 0 & 0 & $-0.50^{\#}$ & $-0.50^{\#}$ \\
\hline hCG & $100 \mathrm{IU} / \mathrm{ml}$ & 4 & 0 & 0 & -0.60 & -0.50 \\
\hline TSH & $10 \mathrm{nM}$ & 2 & 0 & $1(50 \%)$ & n.a. & n.a. \\
\hline Glucagon & $1 \mu \mathrm{M}$ & 4 & 0 & 0 & -0.20 & n.a. \\
\hline GIP & $100 \mathrm{nM}$ & 2 & 0 & 0 & $-1.00^{\natural}$ & n.a. \\
\hline
\end{tabular}

${ }^{* *} \mathrm{p}<0.01$, " standard mixed meal, ${ }^{\#}$ upright posture test, ${ }^{\dagger}$ AVP im, n.a. not applicable.

reacted aberrantly to surges in catecholamines or AngII [2]. Interestingly, in the short-term experiments we found a difference in responsiveness to catecholamines between AIMAH and non-AIMAH cells. In contrast to the observation with AVP, this would suggest the presence of ectopic adrenergic receptors. Previous studies revealed that this could be related to adrenocortical expression of $\beta_{1^{-}}, \beta_{2^{-}}$or $\alpha_{4}$-adrenergic receptors [6,7].

The type 4 serotonin receptor (5HT4R) is expressed in the adrenal gland and its activation can affect cortisol

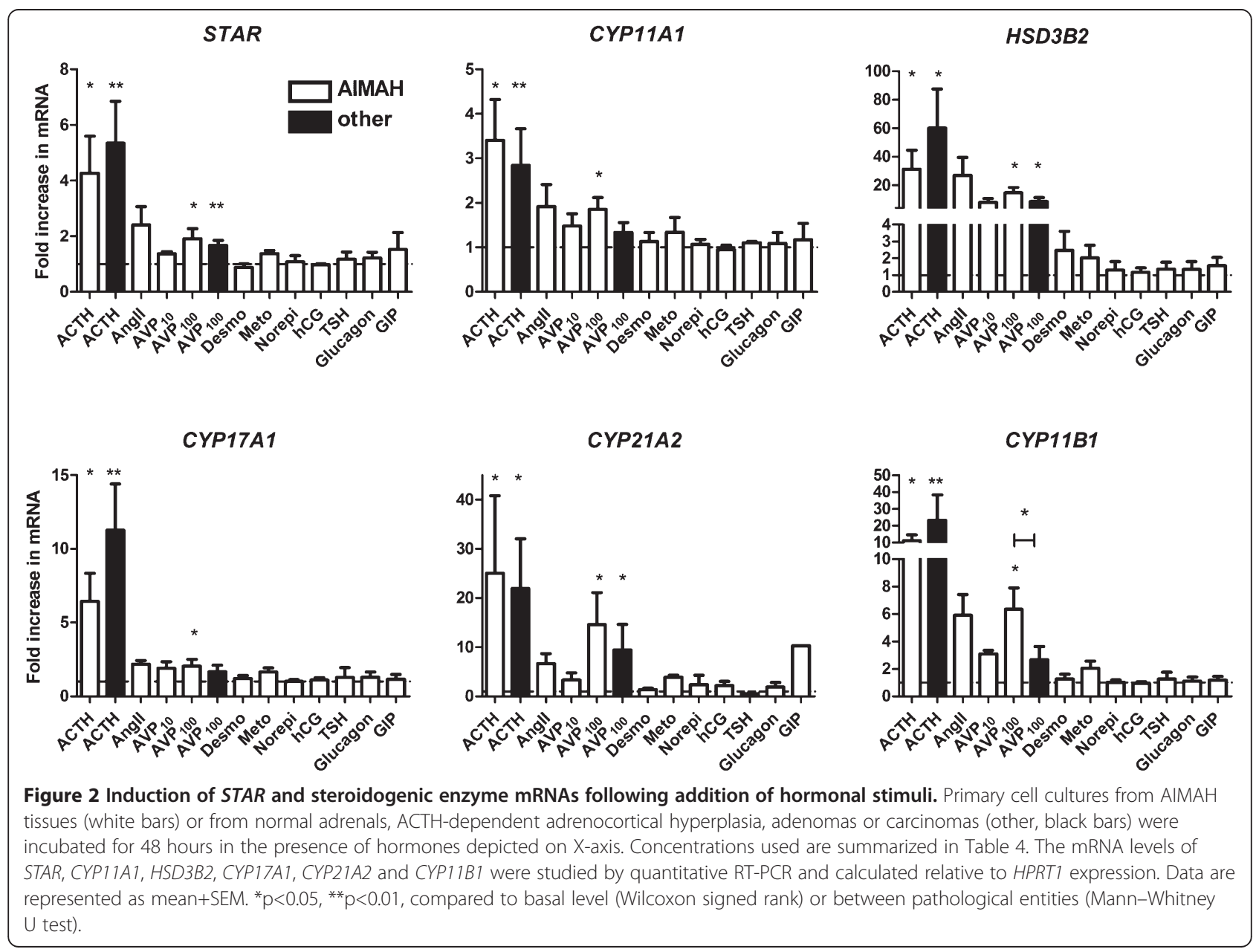




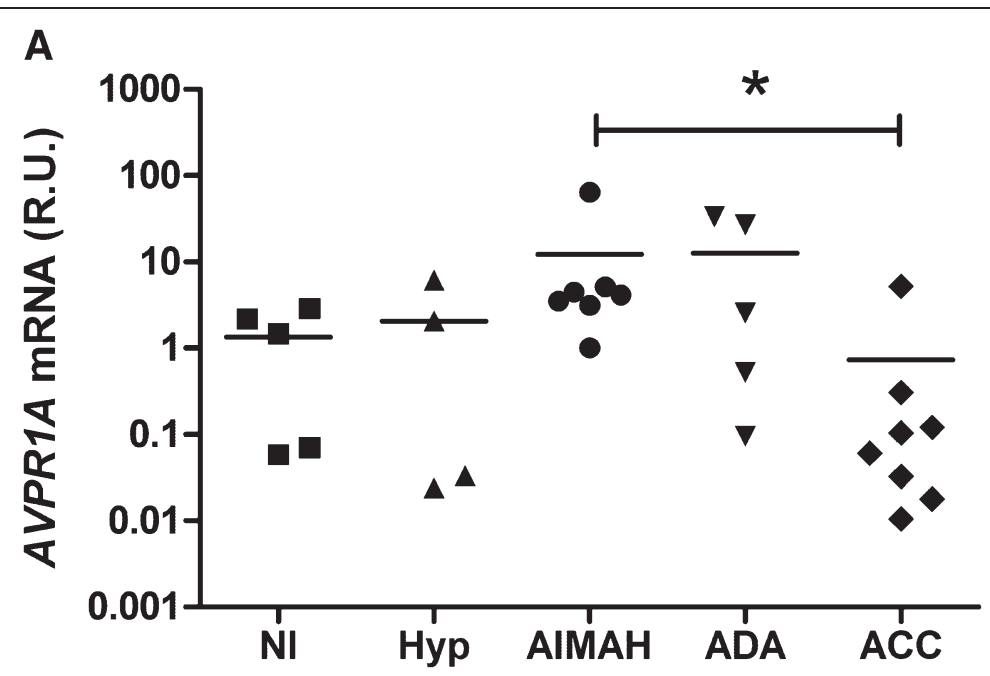

B

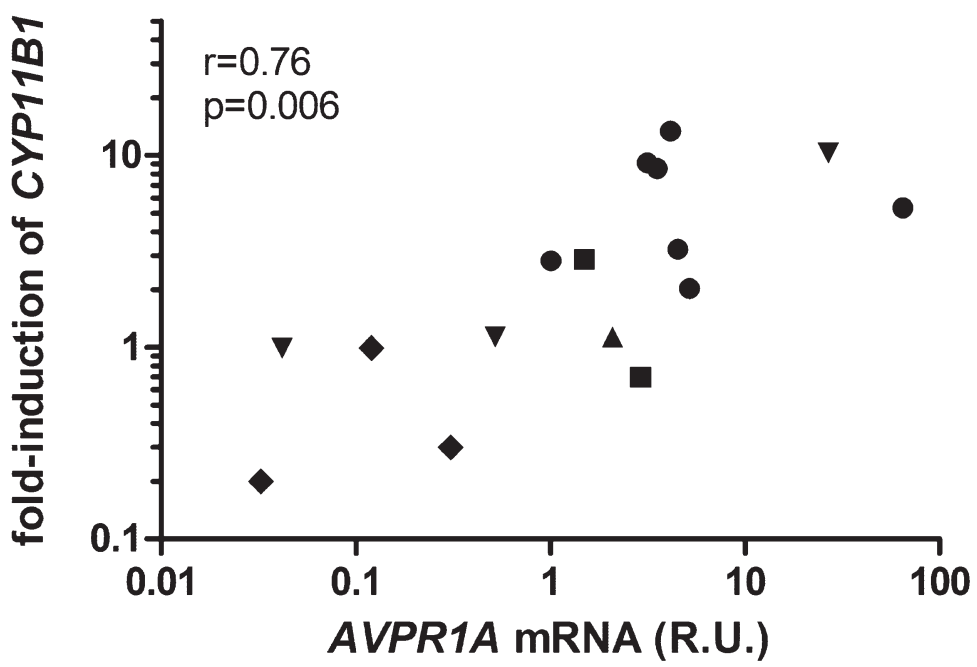

Figure 3 AVP receptor expression in adrenal tissues. (A) AVP type 1a receptor $\left(V_{1}\right.$, AVPRTA) mRNA expression in human adrenocortical tissues (NI: normal, Hyp: ACTH-dependent hyperplasia, ADA: adrenocortical adenoma, ACC: adrenocortical carcinoma), measured by qRT-PCR. R.U.: relative units, compared to HPRT1 expression. ${ }^{*} p<0.05$, Kruskal-Wallis test. $V_{2}$ and $V_{3}$ receptor expression levels were extremely low or undetectable. (B) Significant correlation between AVPRTA expression levels and the induction of CYP11B1 by $100 \mathrm{nM}$ AVP after 48 hours in cultures of primary cells of adrenal tissues. Corresponding icons for individual tissue groups are depicted in Figure A and B.

production [35,36]. In the present study, $34 \%$ of patients had a $>25 \%$ stimulation of serum cortisol levels following metoclopramide, an agonist of 5-HT4R, which was less than the $56 \%$ observed in the previous study [16]. In vitro, this response was also found in AIMAH samples as well as in controls. Moreover, there was no significant difference in response between AIMAH and non-AIMAH cells in vitro, making it questionable whether the response to 5HT in AIMAH patients is truly aberrant.

Other hormonal stimuli can lead to a stimulation of serum cortisol in a minority of AIMAH cases. For LHRH, TRH, glucagon and GIP we have found that this is the case in $10-22 \%$ of patients. Adrenal LHR or GIPR expression was previously confirmed in 6 patients $[5,11,33,37,38]$. The association between cortisol induction following ACTH and after the standard mixed meal could be caused by food-induced stimulation of ACTH $[39,40]$. Unfortunately, we have no data on postprandial ACTH levels in these patients. The inverse correlation between morning cortisol and cortisol induction by a mixed meal reflects higher cortisol increments in patients with low basal cortisol levels. The cause of this finding is unknown, but might reflect higher adrenal sensitivity to GIP at lower cortisol levels. In vitro, we found no major effects of the other hormonal stimuli on cortisol production besides in individual cultures.

The clinical description of AIMAH cases has often been coupled with in vitro investigations on patient 
tissue samples. Several AIMAH patients with discrepancies between clinical and experimental hormonal responses have been described [41,42], which is in contrast to the majority of AIMAH studies in which identical in vitro and in vivo hormonal effects are obtained (reviewed in [2]). We have evaluated in vitro responses in 17 primary cultures of AIMAH tissues and detected a poor overall correlation between clinical and experimental responses to individual stimuli. Possible causes include publication bias of those patients in whom effects could be replicated in vitro, hormonal effects through the pituitary, the concentrations of stimuli used in vitro or the experimental set-up. Since ACTH levels were currently only measured in the in vivo response tests relating to AVP, effects of the other hormonal stimuli through pituitary secretion of ACTH cannot be excluded and might also cause dissociation between clinical and experimental effects. With respect to the latter cause, we also found clear differences and an overall lack of association between short-term and long-term effects of the stimuli on cortisol concentrations. These conclusions should however be drawn with caution due to the small sample sizes of cultures in some of the short- and long-term experiments. Besides the rarity of the disease, the low percentage of patients being operated because of clinical disease and the multitude of testable hormonal stimuli hamper large in vitro studies with all possible secretagogues in AIMAH patients. Also in this study limited availability of cells did not allow for systematic in vitro evaluation of all possible stimuli.

Responses to the aberrant hormonal stimuli were not associated with in vivo hormonal activity since patients with clinical and subclinical CS showed comparable results to stimuli. It should be emphasized that the definition of subclinical CS is controversial as some clinical symptoms of CS can be recognized in patients with subtle cortisol overproduction. In addition, no cut-off values of diagnostic tests have been established that define subclinical hypercortisolism. The findings on in vivo responsiveness to hormonal stimuli are a confirmation of an earlier study [16], in which it was postulated that clinical and subclinical CS represent a continuum of disease rather than two separate entities. This hypothesis is supported by the smaller adrenal sizes detected in subclinical CS patients; these patients could progress into clinical CS when adrenal size and coupled steroidogenic capacity increase.

Exaggerated responses to hormonal stimuli have been reported for multiple cases and case series in adrenal hyperplasia and adenomas, although the responses in healthy individuals have not been investigated for all hormones. It is therefore uncertain to what extent in vivo responses are the results of aberrant expression patterns of hormone receptors. Previous [36,43] and current in vitro data obtained in the non-AIMAH tissues suggest significant effects of AVP and possibly 5-HT. In our analysis we found no differences in responsiveness to hormonal stimuli among ACTH-dependent hyperplasia, adrenal adenoma and carcinoma samples, although numbers were small. Systematic in vivo comparisons for responses between healthy individuals and AIMAH patients might improve the definition of an aberrant response. The arbitrarily used criterion of $>50 \%$ elevation in serum cortisol may also be modified if effects in healthy individuals would be identified.

\section{Conclusions}

Multiple hormonal responses frequently occur in AIMAH patients, with AVP and 5-HT most commonly triggering aberrant eutopic responses. AVP induces steroidogenic enzyme expression in both AIMAH and non-AIMAH adrenocortical tissues. However, in AIMAH there appears to be an aberrant coupling of normal levels of AVPR1A expression to the induction of $C Y P 11 B 1$ expression that may be involved in the pathogenesis of AVP-mediated cortisol overproduction. This may provide an opportunity for medical treatment, targeting the AVP type 1a receptor in a subset of AIMAH patients. Catecholamines appear to represent the most prevalent in vitro ectopic response in AIMAH patients.

\section{Additional file}

Additional file 1: Results of clinical and experimental hormonal stimuli on cortisol induction in individual AIMAH patients.

\section{Competing interests}

The authors declare that there is no conflict of interest that would prejudice the impartiality of this scientific work.

\section{Authors' contributions}

$J H, L J H, P M v K$ \& JS performed the experiments. JH, LJH, PMvK, RRdK, FHvN, CVE, WWdH, MvA, JWdG, TPL and RAF were involved in patient care and/or tissue collection. JH, $L H, W W d H, F H d J$ and RAF designed the study. All authors had the opportunity to revise the manuscript and agree to its final content.

\section{Acknowledgements}

The authors thank all physicians referring patients with AIMAH to our center.

\section{Author details}

${ }^{1}$ Department of Internal Medicine, Section of Endocrinology, P.O. Box 2040, 3000, CA Rotterdam, The Netherlands. ${ }^{2}$ Department of Surgery, Erasmus Medical Center, Rotterdam, The Netherlands. ${ }^{3}$ Department of Pathology, Erasmus Medical Center, Rotterdam, The Netherlands. ${ }^{4}$ Department of Pathology, Reinier de Graaf Gasthuis, Delft, The Netherlands. ${ }^{5}$ Department of Internal Medicine, Haga Hospital, The Hague, The Netherlands. ${ }^{6}$ Department of Internal Medicine, Isala Clinics, Zwolle, The Netherlands. ${ }^{7}$ Department of Internal Medicine, University Medical Center Groningen, University of Groningen, Groningen, The Netherlands.

Received: 25 February 2013 Accepted: 12 September 2013

Published: 13 September 2013 


\section{References}

1. Boscaro M, Arnaldi G: Approach to the patient with possible Cushing's syndrome. J Clin Endocrinol Metab 2009, 94:3121-3131.

2. Lacroix A, Ndiaye N, Tremblay J, Hamet P: Ectopic and abnormal hormone receptors in adrenal Cushing's syndrome. Endocr Rev 2001, 22:75-110.

3. Lacroix A, Bolte E, Tremblay J, Dupre J, Poitras P, Fournier H, Garon J, Garrel D, Bayard F, Taillefer R, et al: Gastric inhibitory polypeptide-dependent cortisol hypersecretion-a new cause of Cushing's syndrome. N Engl J Med 1992, 327:974-980.

4. Reznik Y, Allali-Zerah V, Chayvialle JA, Leroyer R, Leymarie P, Travert G, Lebrethon MC, Budi I, Balliere AM, Mahoudeau J: Food-dependent Cushing's syndrome mediated by aberrant adrenal sensitivity to gastric inhibitory polypeptide. N Engl J Med 1992, 327:981-986.

5. de Herder WW, Hofland $L$, Usdin TB, de Jong FH, Uitterlinden P, van Koetsveld P, Mezey E, Bonner TI, Bonjer HJ, Lamberts SW: Food-dependent Cushing's syndrome resulting from abundant expression of gastric inhibitory polypeptide receptors in adrenal adenoma cells. $\int$ Clin Endocrinol Metab 1996, 81:3168-3172.

6. Lacroix A, Tremblay J, Rousseau G, Bouvier M, Hamet P: Propranolol therapy for ectopic beta-adrenergic receptors in adrenal Cushing's syndrome. N Engl J Med 1997, 337:1429-1434.

7. Assie G, Louiset E, Sturm N, Rene-Corail F, Groussin L, Bertherat J, Thomas M, Lefebvre H, Feige JJ, Clauser E, et al: Systematic analysis of G proteincoupled receptor gene expression in adrenocorticotropin-independent macronodular adrenocortical hyperplasia identifies novel targets for pharmacological control of adrenal Cushing's syndrome. J Clin Endocrinol Metab 2010, 95:E253-262.

8. Horiba N, Suda T, Aiba M, Naruse M, Nomura K, Imamura M, Demura H: Lysine vasopressin stimulation of cortisol secretion in patients with adrenocorticotropin-independent macronodular adrenal hyperplasia. J Clin Endocrinol Metab 1995, 80:2336-2341.

9. Lacroix A, Tremblay J, Touyz RM, Deng LY, Lariviere R, Cusson JR, Schiffrin EL, Hamet P: Abnormal adrenal and vascular responses to vasopressin mediated by a V1-vasopressin receptor in a patient with adrenocorticotropinindependent macronodular adrenal hyperplasia, Cushing's syndrome, and orthostatic hypotension. J Clin Endocrinol Metab 1997, 82:2414-2422.

10. Lacroix $A$, Hamet $P$, Boutin JM: Leuprolide acetate therapy in luteinizing hormone-dependent Cushing's syndrome. N Engl J Med 1999, 341:1577-1581.

11. Feelders RA, Lamberts SW, Hofland $L$, van Koetsveld PM, Verhoef-Post $M$, Themmen AP, de Jong FH, Bonjer HJ, Clark AJ, van der Lely AJ, de Herder WW: Luteinizing hormone (LH)-responsive Cushing's syndrome: the demonstration of $\mathrm{LH}$ receptor messenger ribonucleic acid in hyperplastic adrenal cells, which respond to chorionic gonadotropin and serotonin agonists in vitro. J Clin Endocrinol Metab 2003, 88:230-237.

12. Cartier D, Lihrmann I, Parmentier F, Bastard C, Bertherat J, Caron P, Kuhn JM, Lacroix A, Tabarin A, Young J, et al: Overexpression of serotonin4 receptors in cisapride-responsive adrenocorticotropin-independent bilateral macronodular adrenal hyperplasia causing Cushing's syndrome. J Clin Endocrinol Metab 2003, 88:248-254.

13. Vezzosi D, Cartier D, Regnier C, Otal P, Bennet A, Parmentier F, Plantavid M, Lacroix A, Lefebvre H, Caron P: Familial adrenocorticotropin-independent macronodular adrenal hyperplasia with aberrant serotonin and vasopressin adrenal receptors. Eur J Endocrinol 2007, 156:21-31.

14. Nakamura Y, Son Y, Kohno Y, Shimono D, Kuwamura N, Koshiyama H, Sasano H, Matsuda T: Case of adrenocorticotropic hormone-independent macronodular adrenal hyperplasia with possible adrenal hypersensitivity to angiotensin II. Endocrine 2001, 15:57-61.

15. Miguel V, Redal MA, Viale ML, Kahan M, Glerean M, Beskow A, Fainstein Day $P$ : Aberrant expression of glucagon receptors in adrenal glands of a patient with Cushing's syndrome and ACTH-independent macronodular adrenal hyperplasia. Medicina (B Aires) 2010, 70:254-256.

16. Libe R, Coste J, Guignat L, Tissier F, Lefebvre H, Barrande G, Ajzenberg C, Tauveron I, Clauser E, Dousset B, et al: Aberrant cortisol regulations in bilateral macronodular adrenal hyperplasia: a frequent finding in a prospective study of 32 patients with overt or subclinical Cushing's syndrome. Eur J Endocrinol 2010, 163:129-138.

17. Lacroix A, Bourdeau I, Lampron A, Mazzuco TL, Tremblay J, Hamet P: Aberrant G-protein coupled receptor expression in relation to adrenocortical overfunction. Clin Endocrinol (Oxf) 2010, 73:1-15.

18. Bourdeau I, Antonini SR, Lacroix A, Kirschner LS, Matyakhina L, Lorang D, Libutti SK, Stratakis CA: Gene array analysis of macronodular adrenal hyperplasia confirms clinical heterogeneity and identifies several candidate genes as molecular mediators. Oncogene 2004, 23:1575-1585.

19. Hsiao HP, Kirschner LS, Bourdeau I, Keil MF, Boikos SA, Verma S, RobinsonWhite AJ, Nesterova M, Lacroix A, Stratakis CA: Clinical and genetic heterogeneity, overlap with other tumor syndromes, and atypical glucocorticoid hormone secretion in adrenocorticotropin-independent macronodular adrenal hyperplasia compared with other adrenocortical tumors. J Clin Endocrinol Metab 2009, 94:2930-2937.

20. Gagliardi L, Hotu C, Casey G, Braund WJ, Ling KH, Dodd T, Manavis J, Devitt PG, Cutfield R, Rudzki Z, et al: Familial vasopressin-sensitive ACTHindependent macronodular adrenal hyperplasia (VPs-AIMAH): clinical studies of three kindreds. Clin Endocrinol (Oxf) 2009, 70:883-891.

21. Mazzuco TL, Chabre O, Sturm N, Feige JJ, Thomas M: Ectopic expression of the gastric inhibitory polypeptide receptor gene is a sufficient genetic event to induce benign adrenocortical tumor in a xenotransplantation model. Endocrinology 2006, 147:782-790.

22. Mazzuco TL, Chabre O, Feige JJ, Thomas M: Aberrant expression of human luteinizing hormone receptor by adrenocortical cells is sufficient to provoke both hyperplasia and Cushing's syndrome features. J Clin Endocrinol Metab 2006, 91:196-203.

23. Chiodini I: Clinical review: diagnosis and treatment of subclinical hypercortisolism. J Clin Endocrinol Metab 2011, 96:1223-1236.

24. Lamberts SW, Bons EG, Bruining HA, de Jong FH: Differential effects of the imidazole derivatives etomidate, ketoconazole and miconazole and of metyrapone on the secretion of cortisol and its precursors by human adrenocortical cells. J Pharmacol Exp Ther 1987, 240:259-264.

25. Hofland J, Timmerman MA, de Herder WW, van Schaik RH, de Krijger RR, de Jong FH: Expression of activin and inhibin subunits, receptors and binding proteins in human adrenocortical neoplasms. Clin Endocrinol (Oxf) 2006, 65:792-799.

26. Chai W, Hofland J, Jansen PM, Garrelds IM, de Vries R, van den Bogaerdt AJ, Feelders RA, de Jong FH, Danser AH: Steroidogenesis vs. steroid uptake in the heart: do corticosteroids mediate effects via cardiac mineralocorticoid receptors? J Hypertens 2010, 28:1044-1053.

27. Alwani RA, de Herder WW, de Jong FH, Lamberts SW, van der Lely AJ, Feelders RA: Rapid decrease in adrenal responsiveness to ACTH stimulation after successful pituitary surgery in patients with Cushing's disease. Clin Endocrinol (Oxf) 2011, 75:602-607.

28. Le Roy C, Li JY, Stocco DM, Langlois D, Saez JM: Regulation by adrenocorticotropin (ACTH), angiotensin II, transforming growth factorbeta, and insulin-like growth factor I of bovine adrenal cell steroidogenic capacity and expression of $\mathrm{ACTH}$ receptor, steroidogenic acute regulatory protein, cytochrome $\mathrm{P} 450 \mathrm{c} 17$, and 3beta-hydroxysteroid dehydrogenase. Endocrinology 2000, 141:1599-1607.

29. Hofland J, Delhanty PJ, Steenbergen J, Hofland L, van Koetsveld PM, van Nederveen FH, de Herder WW, Feelders RA, de Jong FH: Melanocortin 2 receptor-associated protein (MRAP) and MRAP2 in human adrenocortical tissues: regulation of expression and association with ACTH responsiveness. J Clin Endocrinol Metab 2012, 97:E747-754.

30. Arnaldi G, Gasc JM, de Keyzer Y, Raffin-Sanson ML, Perraudin V, Kuhn JM, Raux-Demay MC, Luton JP, Clauser E, Bertagna X: Variable expression of the V1 vasopressin receptor modulates the phenotypic response of steroid-secreting adrenocortical tumors. J Clin Endocrinol Metab 1998, 83:2029-2035.

31. Mune T, Murase H, Yamakita N, Fukuda T, Murayama M, Miura A, Suwa T, Hanafusa J, Daido H, Morita H, Yasuda K: Eutopic overexpression of vasopressin v1a receptor in adrenocorticotropin-independent macronodular adrenal hyperplasia. J Clin Endocrinol Metab 2002, 87:5706-5713.

32. Perraudin V, Delarue C, De Keyzer Y, Bertagna X, Kuhn JM, Contesse V, Clauser $\mathrm{E}$, Vaudry $\mathrm{H}$ : Vasopressin-responsive adrenocortical tumor in a mild Cushing's syndrome: in vivo and in vitro studies. J Clin Endocrinol Metab 1995, 80:2661-2667.

33. de Groot JW, Links TP, Themmen AP, Looijenga LH, de Krijger RR, van Koetsveld PM, Hofland J, van den Berg G, Hofland LJ, Feelders RA: Aberrant expression of multiple hormone receptors in ACTH-independent macronodular adrenal hyperplasia causing Cushing's syndrome. Eur J Endocrinol 2010, 163:293-299.

34. Decaux G, Soupart A, Vassart G: Non-peptide arginine-vasopressin antagonists: the vaptans. Lancet 2008, 371:1624-1632.

35. Lefebvre H, Contesse V, Delarue C, Vaudry H, Kuhn JM: Serotonergic regulation of adrenocortical function. Horm Metab Res 1998, 30:398-403. 
36. Lefebvre H, Contesse V, Delarue C, Feuilloley M, Hery F, Grise P, Raynaud G, Verhofstad AA, Wolf LM, Vaudry H: Serotonin-induced stimulation of cortisol secretion from human adrenocortical tissue is mediated through activation of a serotonin4 receptor subtype. Neuroscience 1992, 47:999-1007.

37. Croughs RJ, Zelissen PM, van Vroonhoven TJ, Hofland $\sqcup$, N'Diaye N, Lacroix A, de Herder WW: GIP-dependent adrenal Cushing's syndrome with incomplete suppression of ACTH. Clin Endocrinol (Oxf) 2000, 52:235-240.

38. Messidoro C, Elte JW, Castro Cabezas M, van Agteren M, Lacroix A, de Herder WW: Food-dependent Cushing's syndrome. Neth J Med 2009, 67:187-190.

39. Follenius M, Brandenberger $G$, Hietter B: Diurnal cortisol peaks and their relationships to meals. J Clin Endocrinol Metab 1982, 55:757-761.

40. Ishizuka B, Quigley ME, Yen SS: Pituitary hormone release in response to food ingestion: evidence for neuroendocrine signals from gut to brain. J Clin Endocrinol Metab 1983, 57:1111-1116.

41. Bertherat J, Contesse V, Louiset E, Barrande G, Duparc C, Groussin L, Emy P, Bertagna X, Kuhn JM, Vaudry H, Lefebvre H: In vivo and in vitro screening for illegitimate receptors in adrenocorticotropin-independent macronodular adrenal hyperplasia causing Cushing's syndrome: identification of two cases of gonadotropin/gastric inhibitory polypeptide-dependent hypercortisolism. J Clin Endocrinol Metab 2005, 90:1302-1310.

42. Louiset E, Contesse V, Groussin L, Cartier D, Duparc C, Barrande G, Bertherat J, Vaudry H, Lefebvre H: Expression of serotonin7 receptor and coupling of ectopic receptors to protein kinase $\mathrm{A}$ and ionic currents in adrenocorticotropin-independent macronodular adrenal hyperplasia causing Cushing's syndrome. J Clin Endocrinol Metab 2006, 91:4578-4586.

43. Perraudin V, Delarue C, Lefebvre H, Contesse V, Kuhn JM, Vaudry H: Vasopressin stimulates cortisol secretion from human adrenocortical tissue through activation of V1 receptors. J Clin Endocrinol Metab 1993, 76:1522-1528

doi:10.1186/1750-1172-8-142

Cite this article as: Hofland et al:: ACTH-independent macronodular adrenocortical hyperplasia reveals prevalent aberrant in vivo and in vitro responses to hormonal stimuli and coupling of arginine-vasopressin type 1a receptor to $11 \beta$-hydroxylase. Orphanet Journal of Rare Diseases 2013 8:142.

\section{Submit your next manuscript to BioMed Central and take full advantage of:}

- Convenient online submission

- Thorough peer review

- No space constraints or color figure charges

- Immediate publication on acceptance

- Inclusion in PubMed, CAS, Scopus and Google Scholar

- Research which is freely available for redistribution 